\title{
Feasibility of Warfarin Anticoagulation Management with a Patient Self-Testing Model in Korea
}

\author{
Rojin Park, ${ }^{1}$ So-My Koo, ${ }^{2}$ Mi Ok Hwang, ${ }^{2}$ Dae Chul Seo, ${ }^{2}$ Ki-Up Kim, ${ }^{2}$ Soo-Taek Uh, ${ }^{2}$ Yang-Ki Kim ${ }^{2 *}$ \\ Departments of 'Laboratory Medicine and ${ }^{2}$ Internal Medicine, Soonchunhyang University Seoul Hospital, Seoul, Korea
}

Received: 20 May 2015

Revised: 15 June 2015

Accepted: 16 June 2015

*Corresponding author: Yang-Ki Kim, MD, PhD

Department of Internal Medicine

Soonchunhyang University Seou

Hospital, 59 Daesagwan-ro,

Yongsan-gu, Seoul 140-887, Korea

Tel: +82-2-709-9037

Fax: +82-2-710-3184

E-mail: kyklung@schmc.ac.kr
Copyright (c) Korean Society on Thrombosis and Hemostasis. All rights reserved.
Purpose: Dose adjustments of warfarin are mandatory for effective and safe treatment due to the narrow therapeutic window. Until now, no domestic data have been reported on warfarin anticoagulation management using a patient self-testing (PST) model. Here, we describe our experiences with warfarin management with a PST model.

Methods: Data were collected retrospectively from 13 patients who had been anti-coagulated with warfarin from Jan 1, 2010 to May 30, 2011. Time in therapeutic international normalized ratio (INR) range (TTR) and thromboembolic or bleeding complications were considered as the primary and secondary outcomes, respectively. The INR values obtained by point-of-care (POC) self-testing at home were sent to the anticoagulation clinic by telephone and the patients were informed of their warfarin dosage changes and next scheduled INR testing date by the anticoagulation clinical staff. Warfarin dose-adjustment and INR determination were performed according to the recommendations of the warfarin dosage-adjustment algorithm introduced in the previous study.

Results: The average interval of POC INR monitoring per patient was $14.2 \pm 5.1$ days. Our results showed that well-trained patients could obtain their INRs by self-testing, and the mean TTR was $67.0 \%$. During the follow-up period, neither recurrent venous thromboembolism nor bleeding complications were noted. There was one case of mortality due to the progression of gastric cancer that was diagnosed during warfarin treatment.

Conclusion: The present study is the first to report on warfarin management using the PST model in Korea. PST model is considered to be a promising tool for maintaining adequate TTR.

Keywords: Warfarin, Anticoagulation, TTR, POC INR test, Thromboembolism

\section{Introduction}

Warfarin is the main oral anticoagulant effective for the prevention of stroke in patients with atrial fibrillation, and for the prevention and treatment of venous thromboembolism. It has a narrow therapeutic window of effectiveness and safety, which may lead to underuse. Accordingly, dose adjustments are mandatory for its effective and safe treatment, which depends on the time spent in the therapeutic International Normalized Ratio (INR) range (TTR). Hence, TTR is a key determinant of outcomes for patients receiving anticoagulation with warfarin. ${ }^{1}$ It is well known that lower rates of TTR in warfarin patients leads to an increased risk of bleeding or thromboembolic complications. ${ }^{2}$ Many studies have reported on the accuracy and precision of point-of-care (POC) devices when used by patients for INR monitoring on warfarin anticoagulation, ${ }^{3-5}$ as well as their good correlations with conventional plasma INR measurements within therapeutic ranges. ${ }^{6-9}$ Previous studies have indicated that a patient self-testing model may be superior to usual care or an anticoagulation clinic model in the quality of INR control..$^{10}$ Recently, there has been increasing demand for high-quality warfarin management in Korea. Nevertheless, no domestic data have been reported on warfarin anticoagulation management using a patient self-testing (PST) model. Here, we describe our experiences with warfarin management using a PST model where the warfarin dose was adjusted by the anticoagulation clinic staff on the basis of a validated algorithm with the INR values self-tested by patients at home using capillary blood on the POC device CoaguChek-XS (Roche Diagnostics, Mannheim, Germany).

\section{Methods}

This study was approved by the Soonchunhyang University Seoul Hospital Institutional Review Board. Data were collected retrospectively from 13 outpatients who had been anti-coagulated with warfarin from January 1, 2010 to May 30, 2011. TTR was considered as the primary outcome and was calculated using a modification of the Rosendaal's linear interpolation method. ${ }^{11}$ This method assumes that there is a linear relationship between two consecutive INR results and determines the proportion of time for which the INR is below, within or above the therapeutic range. Thromboembolic or bleeding complications were considered secondary outcomes in the present investigation. ${ }^{12}$ Inclusion criteria were as follows: 1) patients in need of anticoagulant therapy for at least 6 months; 2) patients who had limited access to clinical services due to distance; 3 ) patients who could not move freely; 4) patients who understood the importance of anticoagulant control; or 5) patients who (or whose guardians) understood and could safely perform POC INR tests. Patients with indications for oral anticoagulation therapy were instructed on the 
Table 1. Baseline characteristics of the patients $(n=13)$

\begin{tabular}{lc}
\hline \multicolumn{2}{l}{ Characteristics } \\
\hline Male, $\mathrm{n}(\%)$ & $5(38)$ \\
Age, median (range) & 71 (28-84) \\
Indication of warfarin, $\mathrm{n}(\%)$ & $3(23)$ \\
$\quad$ Atrial fibrillation & $10(77)$ \\
$\quad$ Venous thromboembolism (PE or DVT) & $9(3-20)$ \\
Duration of treatment, median months (range) & \\
Co-morbid condition (n) & 1 \\
Active malignancy (within 6 months) & 2 \\
Chronic obstructive pulmonary disease & 1 \\
Congestive heart failure & 4 \\
Cerebrovascular accident or transient ischemic attack & 1 \\
Ischemic heart disease & 2 \\
Renal insufficiency (GFR $<30 \mathrm{~mL} / \mathrm{min})$ & \\
\hline
\end{tabular}

n, number; PE, pulmonary embolism; DVT,deep vein thrombosis; GFR, Glomerular filtration rate.

benefits and risks of warfarin, the importance of warfarin dose adjustments, warfarin precautions, and potential interactions between warfarin and foods or other drugs. Patients were instructed on how to perform POC INR self-tests. The INR values obtained by POC INR self-testing at home were sent to the anticoagulation clinic by telephone and the patients were informed of their warfarin dosage changes and next scheduled INR test date by the anticoagulation clinical staff. Warfarin dose-adjustment and INR determination were performed according to the recommendations of the warfarin dosage-adjustment algorithm introduced in the previous study. ${ }^{13}$ The warfarin dosage-adjustment algorithm is designed for use in patients already stabilized on warfarin, and takes into account the patients' most recent INR results and the previous weekly warfarin dose prescription. Briefly, the algorithm recommends no dose change when the INR is in the therapeutic range, a $10 \%$ adjustment in the weekly dose of warfarin when two consecutive INR results are out of range by no more than 0.5 units below or 1.0 unit above the therapeutic INR range, and a 10-20\% adjustment in the weekly dose of warfarin when the deviation from the therapeutic INR range is more extreme. For very high INRs, warfarin is held and/or vita$\min \mathrm{K}$ is administered as appropriate.

\section{Results}

In the present study, enrolled patients consisted of 5 males and 8 females aged 28-84 (mean age 67). Venous thromboembolism and atrial fibrillation were the indications for warfarin, accounting for 10 and 3 of the patients, respectively. Patients were followed for a period of 3-20 months. They had comorbid conditions such as chronic obstructive pulmonary disease, congestive heart failure, cerebrovascular accident, ischemic heart disease and renal insufficiency (Table 1). During the study period, the total number of INR measurements was 271 and the total number of evaluated patient days was 3,512 . The average INR follow-up interval per patient was 14.2 \pm 5.1 days. Individual patient TTR ranged from 35.0-92.3\% (mean $\pm \mathrm{SD}, 64.5 \pm 19.4$ ), while the mean percentage TTR was $67.0 \%$ (Fig. 1 and 2). Neither recurrent venous thromboembolism nor bleeding complications were noted. There was one case of mortality due to advanced gastric cancer that was diagnosed during warfarin treatment.

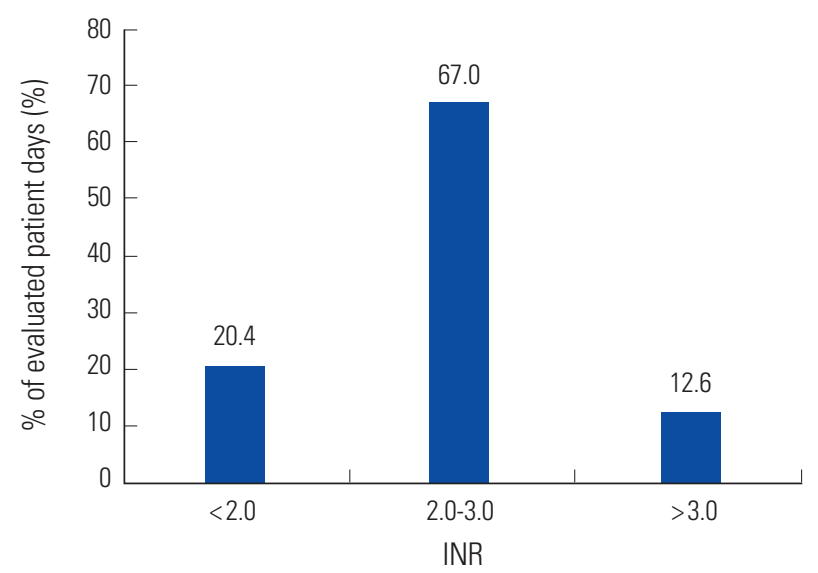

Fig. 1. International normalized ratio (INR) histogram for patients on warfarin. Mean interval between INR checks is $14.2 \pm 5.1$ days.

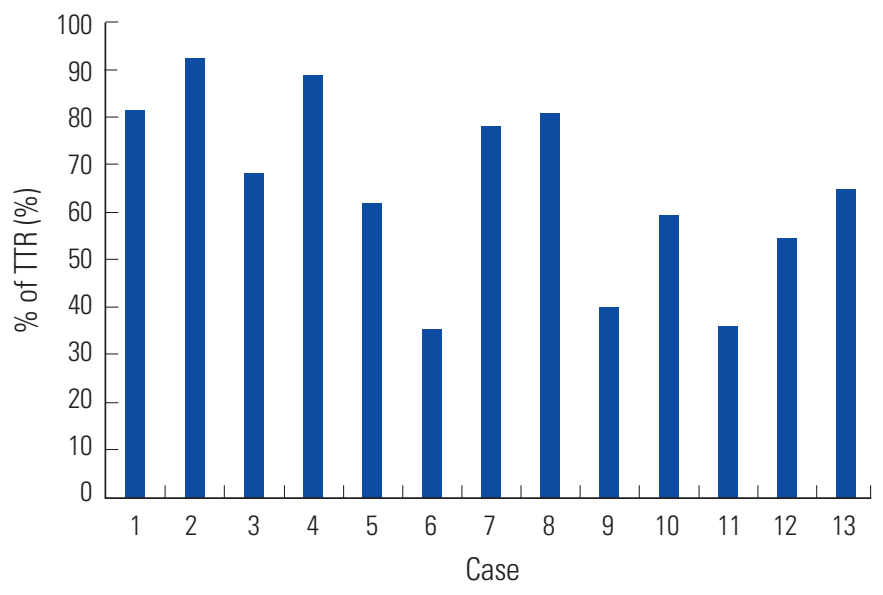

Fig. 2. Individual TTR in patients on warfarin. TTR was calculated using a modification of the Rosendaal's linear interpolation method.

\section{Discussion}

There have been several evolving models that argue against usual care for warfarin anticoagulation management, including PST, patient self-management, anticoagulation clinic, and computerized dose adjustments models. ${ }^{14}$ These models have been proven to significantly improve TTR as compared to usual care. ${ }^{15,16}$ In the current study, when we applied the PST model to warfarin management, the patients achieved a mean TTR of $67.0 \%$. This result is comparable to the TTR range of 55-70\% usually achieved by patients in the PST model in previous reports. ${ }^{1}$ Consistent with the previous report, ${ }^{17}$ our study results showed that well-trained patients could obtain their INRs by self-testing. We concluded that PST model is considered to be a promising tool for maintaining adequate TTR. PST of anticoagulation is primarily based on the premise that more frequent testing will lead to tighter anticoagulation control and thus improved clinical outcomes. ${ }^{12}$ Frequent monitoring is required to maintain patients in the therapeutic window. It has been demonstrated that $77-85 \%$ of patients can be expected to remain in their target range if monitoring of INR occurs weekly, and up to $92 \%$ can remain in their target range if monitored every 3 days. ${ }^{18}$ 
Due to individual variations of TTR ranging from 35.0 to $92.3 \%$, we evaluated the patients' compliance with warfarin therapy to assess whether there were associations between compliance and the unexpectedly wide fluctuations in INRs. There was no causal relationship between compliance (compliance, \%: $70.6 \pm 16.9$ [mean \pm $\mathrm{SD}$ ], 45.5-92.0 [range]) and TTR, suggesting that a number of factors such as co-morbid conditions, poor compliance, alcohol, drug interactions, variable dietary intake, inadequate education about warfarin therapy, and miscommunication between the patient and anticoagulation clinic staff could affect INR control in warfarin patients. The percentages of INR values in the sub-therapeutic $(<2.0)$ and supra-therapeutic $(>3.0)$ ranges were $20.4 \%$ and $12.6 \%$, respectively, in this study, suggesting that warfarin treatment was underprescribed. In older patients, unstable anticoagulation control and monitoring problems may cause drug safety concerns and lead to under-prescription. The risk of life-threatening bleeding complications, including subdural hematoma and intracranial hemorrhage, is increased in those with unstable anticoagulation control. ${ }^{19}$

There are some barriers to the PST model of warfarin manage- ment, including a lack of physician awareness, the fear of unintended self-management, and the expense and education needed to implement PST. Under such circumstances, PST is currently not wellestablished in Korea, despite the availability of POC INR devices that have been demonstrated to be accurate and reliable. Above all, adequate patient education and training is essential to the success of patient self-testing. In recent studies, it has been stressed that patient education is essential in improving patient knowledge regarding the importance of warfarin therapy, and in turn, improving compliance, all of which lead to optimal anticoagulation control. ${ }^{20,21}$ In conclusion, the present study is the first report on warfarin management using the PST model in Korea and suggests that PST is a feasible, accurate, and promising tool for maintaining adequate TTR. Further study with a larger number of patients is warranted to develop optimal warfarin management strategies in Korea.

\section{Conflicts of Interest}

There are no conflicts of interest relevant to this article to report.

\section{References}

1. Ansell J, Hirsh J, Hylek E, Jacobson A, Crowther M, Palareti G. Pharmacology and management of the vitamin K antagonists: American College of Chest Physicians Evidence-Based Clinical Practice Guidelines (8th Edition). Chest 2008;133:160S-98S.

2. Wan Y, Heneghan C, Perera R, Roberts N, Hollowell J, Glasziou P, et al. Anticoagulation control and prediction of adverse events in patients with atrial fibrillation: a systematic review. Circ Cardiovasc Qual Outcomes 2008;1:84-91.

3. Gosselin R, Owings JT, White RH, Hutchinson R, Branch $\mathrm{J}$, Mahackian $\mathrm{K}$, et al. A comparison of point-of-care instruments designed for monitoring oral anticoagulation with standard laboratory methods. Thrombo Haemost 2000;83:698-703.

4. van den Besselaar AM. A comparison of INRs determined with a whole blood prothrombin time device and two international reference preparations for thromboplastin. Thromb Haemost 2000; 84:410-2.

5. Oral Anticoagulation Monitoring Study Group. Pointof-care prothrombin time measurement for professional and patient self-testing use. A multicenter clinical experience. Oral Anticoagulation Monitoring Study Group. Am J Clin Pathol 2001;115:288-96.

6. Bereznicki LR, Jackson SL, Peterson GM, Jeffrey EC, Marsden KA, Jupe DM. Accuracy and clinical utility of the CoaguChek XS portable international normalised ratio monitor in a pilot study of warfarin home-monitoring. J Clin Pathol 2007;60:311-4.
7. Hentrich DP, Fritschi J, Muller PR, Wuillemin WA. INR comparison between the CoaguChek $\mathrm{S}$ and a standard laboratory method among patients with self-management of oral anticoagulation. Thromb Res 2007;119: 489-95.

8. Jackson SL, Bereznicki LR, Peterson GM, Marsden KA, Jupe DM, Tegg E, et al. Accuracy, reproducibility and clinical utility of the CoaguChek S portable international normalized ratio monitor in an outpatient anticoagulation clinic. Clin Lab Haematol 2004;26:49-55.

9. Park R, Kim Y, Kwon K, Na J, Won Y, Sung K, et al. Utility of CoaguChek XS for Monitoring the Prothrombin Time. Tuberc Respir Dis 2008;65:471-5.

10. Siebenhofer A, Rakovac I, Kleespies C, Piso B, Didjurgeit U. Self-management of oral anticoagulation in the elderly: rationale, design, baselines and oral anticoagulation control after one year of follow-up. A randomized controlled trial. Thromb Haemost 2007;97:408-16.

11. Rosendaal FR, Cannegieter SC, van der Meer FJ, Briet E. A method to determine the optimal intensity of oral anticoagulant therapy. Thromb Haemost 1993;69:236-9.

12. Samsa GP, Matchar DB. Relationship between test frequency and outcomes of anticoagulation: a literature review and commentary with implications for the design of randomized trials of patient self-management. J Thromb Thrombolysis 2000;9:283-92.

13. Kim YK, Nieuwlaat R, Connolly SJ, Schulman S, Meijer K, Raju N, et al. Effect of a simple two-step warfarin dosing algorithm on anticoagulant control as measured by time in therapeutic range: a pilot study. J Thromb Haemost 2010;8:101-6.

14. Ansell J, Hirsh J, Poller L, Bussey H, Jacobson A, Hylek
E. The pharmacology and management of the vitamin K antagonists: the Seventh ACCP Conference on Antithrombotic and Thrombolytic Therapy. Chest 2004;126: 204S-33S.

15. van Walraven C, Jennings A, Oake N, Fergusson D, Forster AJ. Effect of study setting on anticoagulation control: a systematic review and metaregression. Chest 2006; 129:1155-66.

16. Manotti C, Moia M, Palareti G, Pengo V, Ria L, Dettori AG. Effect of computer-aided management on the quality of treatment in anticoagulated patients: a prospective, randomized, multicenter trial of APROAT (Automated PRogram for Oral Anticoagulant Treatment). Haematologica 2001;86:1060-70.

17. Gardiner C, Williams K, Mackie IJ, Machin SJ, Cohen $\mathrm{H}$. Patient self-testing is a reliable and acceptable alternative to laboratory INR monitoring. Br J Haematol $2005 ; 128: 242-7$

18. Oral Anticoagulation Monitoring Study Group. Prothrombin measurement using a patient self-testing system. Am J Clin Pathol 2001;115:280-7.

19. Fihn SD, McDonell M, Martin D, Henikoff J, Vermes $\mathrm{D}$, Kent D, et al. Risk factors for complications of chronic anticoagulation. A multicenter study. Warfarin Optimized Outpatient Follow-up Study Group. Ann Intern Med 1993;118:511-20.

20. Barcellona D, Contu P, Marongiu F. Patient education and oral anticoagulant therapy. Haematologica 2002 87:1081-6.

21. Arnsten JH, Gelfand JM, Singer DE. Determinants of compliance with anticoagulation: A case-control study. Am J Med 1997;103:11-7. 